\title{
Disagreement, Unenforceability, and Harm Reduction
}

\author{
Daniel M. Weinstock ${ }^{1}$
}

Accepted: 10 October 2020 / Published online: 24 October 2020

(c) Springer Science+Business Media, LLC, part of Springer Nature 2020

\begin{abstract}
Talk of harm reduction has expanded horizontally, to apply to an ever-widening range of policy domains, and vertically, becoming part of official legal and political discourse. This expansion calls for philosophical theorization. What is the best way in which to characterize harm reduction? Does it represent a distinctive ethical position? How is it best morally justified, and what are its moral limits? I distinguish two varieties of harm reduction. One of them, technocratic harm reduction, is premised on the fact of non-enforceability of prohibitionist policies. The second, deliberative harm reduction, is premised on the fact of reasonable disagreement, grounded in the fact that reasonable persons disagree about a range of controversial behaviours. I argue that deliberative harm reduction better accounts for some of harm reduction's most attractive features, and provides a plausible way of accounting for harm reductions's justificatory grounds and limits.
\end{abstract}

Keywords Harm reduction · Consequentialism · Disagreement · Enforcement · Policy

\section{Introduction}

Harm Reduction is having a moment. Initially thought of as a practice aimed at meeting the needs of drug users without resorting to the punitive, prohibitive approach taken by states [1, 18, 19], it is now being invoked in a wide range of different contexts. More specifically, it is undergoing both vertical and horizontal expansion. The vertical expansion consists in the fact that harm reduction has now migrated up the policy ladder and has entered into the lexicon of officialdom. It is no longer solely the preserve of street-level practitioners directly with street involved

\footnotetext{
This paper was originally presented at a workshop on harm reduction that I co-organized with Shannon Dea. Thanks are due to the participants at the workshop. Thanks are also due to two anonymous referees for this Journal, whose comments improved the paper immeasurably.

Daniel M. Weinstock

Daniel.weinstock2@mcgill.ca

1 Institute for Health and Social Policy, Faculty of Law, McGill University, Montreal, Canada 
drug users. In Canada, for example, it became a term commonly used by Jane Philpott, Justin Trudeau's first Health Minister, ${ }^{1}$ and it is arguably operative in a trio of decisions of the Supreme Court of Canada, to do with safe injection sites, sex work, and medical assistance in dying. ${ }^{2}$

The horizontal expansion has had to do with the range of practices to which talk of harm reduction has been seen by some to be appropriate. No longer confined solely to drug use, harm reduction has been seen by some as an appropriate approach to adopt across a wide range of practices, including sex work [3], female genital cutting [20], domestic violence [7], medical assistance in dying [9, 15], abortion [4], and even risky behaviour in the context of the COVID-19 pandemic [13].

This expansion in the presence of harm reduction talk across a wide range of policy domains and contexts has thus far not been met by a concomitant increase in theoretical discussion of the concept. Philosophical attention in particular has been scant $[2,4,12,17]$.

My intention in this short paper is to contribute to filling this theoretical gap. I will proceed as follows. First, I will distinguish two distinct rationales that may be adduced to justify making use of harm reduction policies with respect to some problematic practice (as opposed, at one end of the spectrum, to having no policy with respect to the practice, or, at the other end, to adopting a prohibitionist policy with respect to it). These competing rationales invoke the fact of reasonable disagreement (FRA) on the one hand, and the fact of unenforceability (FU) on the other. Second, I will argue that a theory and practice of harm reduction grounded in FRA is normatively superior and conceptually more distinctive than an approach grounded in FU.

\section{Two Rationales for Harm Reduction}

As a conceptual matter, talk of harm reduction gets off the ground because some practice is deemed to be problematic, but enforcement of a prohibition with respect to the practice in question is deemed to be inappropriate. There is no controversy over enforcement in two, diametrically opposed kinds of cases. First, in cases in which a practice is seen as entirely innocuous, or even admirable, and carrying no risks, the question of prohibition and enforcement obviously does not arise. Call these cases of clear permission. Second, in cases in which a practice is clearly and uncontroversially wrong, and with respect to which prohibitions are known to be effective, prohibition is clearly called for. Call these cases of clear prohibition.

Harm reduction would seem to be called for, at least prima facie, when we find ourselves in a middle ground between clear permission and clear prohibition. It could either be the case that there is reasonable disagreement as to whether the practise in question should be condemned, or that there is some obstacle to effective

\footnotetext{
1 See for example her statement about the opioid crisis in Canada. https://www.cbc.ca/news/politics/ injection-consumption-site-passed-1.4122528.

2 Canada (Attorney General) v. PHS Community Services Society 2011 SCC 44; Canada (Attorney General) v. Bedford 2013 SCC 72; Carter v. Canada (Attorney General) 2015 SCC 5.
} 
enforcement of a prohibition on the practise, or both. I will refer to these two cases as appealing to the fact of reasonable disagreement or the fact of unenforceability. Let me expand both of these distinct routes to the conclusion that harm reduction is called for.

The Fact of Reasonable Disagreement: a feature shared by of many of the practices to which it has been thought that harm reduction should be applied is that they are the object of reasonable disagreement. Many of these practices engage deeply held values that are, on the face of it, irreconcilable. For example, those who defend the right of sex workers to practice their profession in safe and respectful conditions will invoke considerations of individual autonomy and consent. According to this view, persons who engage in sex work should be allowed to make their own choices as to how to use their bodies, and they should be allowed to do so free from moralistic policies that criminalize what are essentially victimless crimes. Those who oppose it will emphasize dignity, and the fundamental importance of not treating bodies like commodities. There seems little way of bridging the conceptual gap between these two views. ${ }^{3}$ Similar value dualities can be uncovered underlying other practices for which it has been thought that harm reduction might be appropriate., ${ }^{4},{ }^{5}$ For example, debates over medical assistance in dying pit against one another those who believe that a society committed to rational autonomy cannot deny its citizens the right to decide for themselves how they will face grave illness and death, with those who argue that human life should be treated by the state as inviolable. ${ }^{6}$ Similar debates have taken place over the attitude that the state should take to the use of recreational drugs such as marijuana. ${ }^{7}$ What is distinctive about these debates is that they have to do with positions that are solidly anchored in values that reasonable persons can affirm. Though participants in these debates will often say of the other that their positions are unreasonable and untenable, what makes them so difficult to deal with in societies that recognize even a modicum of value pluralism is that, when one looks at them as it were "from the outside", it is not possible to rule either one of them out of court as being inadmissible. Thus, outright prohibition is with respect to the practices that fall within the ambit of reasonable pluralism problematic, since it would seem to deny the equal status of those who hold, reasonably, that the practice in question should be allowed.

Now, this is not to deny that defenders of permission can sometimes see the practices in question as risky. What they deny is that the values upon which they are grounded, in an of themselves, disqualify the practice. Thus, for example, defenders of abortion rights can hold that women have the right to determine whether or not they will bring a pregnancy to term, while at the same time recognizing that there

\footnotetext{
3 See Flanigan and Watson [6] for the ethical debate around sex work.

4 Dea argues that what at first glance might present itself as an irreconcilable conflict among categorically construed values is always already a debate about harms. I disagree, but cannot take up the debate in the context of this short paper [4].

5 Determining the bounds of the "reasonable" is one of the most vexed questions in contemporary moral and political philosophy. I have contributed to the debate in Weinstock [21].

6 See Dworkin et al. [5] for the ethical debate over medical assistance in dying.

7 See Husak and de Marneffe [10] for the ethical debate around drug use.
} 
are risks of harms associated with it [3]. This recognition grounds the stance of regulated rather than unregulated permission-in effect, harm reduction.

Unenforceability: the conclusion that harm reduction rather than the enforcement of prohibition is the optimal policy approach to a policy issue can also come about through the recognition that though the practice in question is grounded in values that fall beyond the range of reasonable views, enforcement is either impossible or prohibitively costly. The financial costs of the "War on Drugs" have for example been well documented. The conclusion that enforcement of a prohibition is not the right route to adopt can be arrived at in a variety of ways. In some cases, it might be via the recognition that though it might be technically possible to enforce a prohibition on a given territory, enforcement is likely to lead to those who are inclined to take part in the practice engaging in it in another jurisdiction, where the practice in question is not prohibited. This is a concern that led some observers to defend the so-called "Seattle compromise" in the case of female genital cutting.

In some cases, it is not so much that the enforcement of a prohibition is impossible, but rather that it would involve excessive costs. The enforcement of prohibitions may to begin with be excessively costly in monetary terms, for example because it requires the setting up of massive apparatuses of surveillance and enforcement. But it may also be prohibitively costly in terms of the infringement of civil rights that it requires. For example, the amount of surveillance that would be required in order effectively to enforce a prohibition against casual drug use, or against sex work, would make a mockery of liberal guarantees of the privacy rights of citizens [12]. The futility and destructiveness of attempting to declare a "war on drugs" is readily apparent to anyone who examines the data of the last few decades of attempts at prohibition [8, 10]. And though there is some evidence that prohibitionist models have reduced the incidence of sex work in the countries that have put in place the so-called "Nordic model", there is also evidence that the conditions that the model imposes upon the persons who continue to work in the sex industry are worse than they are under a more permissive model $[9,11]$. In general, one of the motivations for a harm reduction approach is the recognition that failed enforcement, even where enforcement is all things equal desirable, can lead to the worst of all possible outcomes, namely one of unregulated non-compliance, and that in order to avoid this worst-case scenario the most rational policy approach is to try to minimize the harms associated with a practice through regulation-in other words to engage in harm reduction.

It should be noted that these two "paths" to harm reduction are not mutually exclusive. Indeed, it could very well be the case that there is reasonable disagreement over the question of whether a practice is morally condemnable or not, and that attempts at prohibiting that selfsame practice are judged by all, including by those who would ideally prefer to prohibit it, to be excessively costly, or even impossible. And thus, one can very well imagine an agreement to regulate a practice rather than permitting it outright or prohibiting it being reached for different reasons by parties who come to the conclusion that harm reduction is the most appropriate approach.

$F R D$ and $F U$ thus provide two distinct normative roads to harm reduction. The first can be seen as putting forward the following proposition: "since reasonable persons disagree about the fundamental principles that ought to be brought to bear in 
the moral evaluation of practice $\mathrm{x}$, the pursuit of policy relative to $\mathrm{x}$ that is acceptable to reasonable persons should "change the subject", and emphasize consequentialist considerations to do with different ways in which to regulate the practice, rather than continuing down the futile road of trying to determine who is right about the moral acceptability of the practice". The second justifies harm reduction in a different manner. Those who defend harm reduction by emphasizing problems relating to enforceability are likely to argue as follows: "it would be preferable to enforce a prohibition with respect to $\mathrm{x}$, but given that we can't, or that to do so would be too costly, it is preferable, all things considered, to minimize the harms associated with $\mathrm{x}$, rather than attempting to continue to enforce the prohibition".

What I want to suggest in the following section is that harm reduction policies grounded in FRD are preferable to such practices when they are grounded in FU. In determining how to implement harm reduction policies, how to justify them, how to institutionalize them, and how to limit them, FRD provides better answers than does FU.

\section{Why Harm Reduction Should be Grounded in the Fact of Reasonable Disagreement Rather than in the Fact of Unenforceability}

I want in this section to suggest that harm reduction grounded in the fact of disagreement is preferable to harm reduction grounded in unenforceability. I will do so in three ways. First, I will show that the attitude that FRD-grounded harm reduction provides us with a better theoretical interpretation of the largely untheorized harm reduction practices on the basis of which the harm reduction approach first got its impetus. Second, I will show that it captures better than does a FU-grounded approach the limits that could reasonably be taken to attach to harm reduction. Third, I will suggest that the politics that seem to be suggested by reasonable disagreement are preferable to those that flow most naturally from a justification of harm reduction grounded in the fact of unenforceability.

\section{(a) Harm Reduction as Non-Judgmental}

One of the distinguishing features of harm reduction as it was originally construed as an approach to drug use is its non-judgmental character. The deployment of harm reduction strategies is not predicated on a negative moral assessment of the character of those who engage in drug use (or, by extension, in any of the other controversial practices to which harm reduction has been, or could be, extended). Nor is cessation of the practice viewed as an objective of the practice. Rather, it is recognized by those who engage in harm reduction that those who engage in the practice are not to be judged as morally lacking in virtue of their participation in it, and that though there are harms that can be associated with the practice, these are risks that do not flow from any intrinsic moral flaw inherent in the practice, but rather from the fact that engaging even in morally innocuous practices in a social context can, if 
the practice is unregulated, produce harms. On the harm reduction approach, this is as true of sex work and drug use as it is of skateboarding [14].

Defenders of FU-grounded harm reduction do not share this perspective on the practices that they would regulate. Ex hypothesi, they condemn the practices in question, and only accede to the necessity of regulating it because they recognize that the enforcement of a prohibition is likely, if attempted, to give rise to sub-optimal results, ones in which the practice in question persists, but in which its worst consequences are allowed to manifest themselves because, by pursuing a prohibitionist agenda, the state will have denied itself the tools of regulation. It remains the case that for the defender of the FU version of harm reduction, the eradication of the frowned-upon practice is always the ideal. The enforcement of prohibition is never completely taken off the table, and can, on this way of construing harm reduction as a pis aller rather than as a first-best option, always be brought back into the policy agenda were empirical circumstances making prohibition unattractive to change.

Now, it might appear as if the FRD approach is not entirely exempt of the judgmental and moralizing stance that I have just ascribed to the FU approach. After all, to the extent that it is grounded in disagreement, there will always be at least one party to the disagreement that views the practice being regulated as morally condemnable, and that wishes for its disappearance.

There are in fact two possibilities here that should be carefully distinguished. In one of them, as has already been suggested, an "overlapping consensus" arises between defenders of FRA- and FU-grounded conceptions of harm reduction as to the preferability of opting for harm reduction in a given policy context. This is a hybrid case, one in which one party to a policy dispute affirms harm reduction on FRD grounds whereas the other does so on FU grounds. In another, which, I would argue, represents the "pure" FRD-based base, both parties to the debate recognize that reasonable persons can very well affirm the values that their opponents affirm, and the practices that flow from these values. The latter case involves a complex, but recognizable combination of attitudes. On the one hand, the opponent believes that it would be better if people did not engage in practice $\mathrm{x}$, but understands and appreciates that on the basis of a set of values or ranking of values different from her own, one can very well arrive at the conclusion that the practice is acceptable. This complex moral attitude in my view differs from outright condemnation, in which the party in question comes to the conclusion that no reasonable person could possibly affirm these values or the corresponding practices. It is therefore compatible with the non-judgmental ethos that has been central to the harm reduction approach since its inception.

If the foregoing is at all plausible, I will have shown that FRD-based harm reduction offers a better theoretical working up of the moral impetus at the heart of harm reduction in its original manifestation than does the FU-based version. It also brings to light what is truly distinctive about the harm reduction approach. It will not have escaped the attention of the careful reader that FU-based harm reduction is at the 
end of the day just another version of consequentialism. ${ }^{8}$ The defender FU-based version arrives in specific cases at the conclusion that harm reduction is called for because she estimates that the negative consequences associated with unsuccessful enforcement are worse than those that would flow from regulation. FRD-based harm reduction, on the other hand, while it incorporates consequentialist elements (the goal is after all to reduce harms), couches the exercise through which harms are assessed in a theory that manifests mutual respect-respect for those of our fellow citizens who disagree with us about the basic values in play in a policy debate, but also respect for those who engage in the disputed practice, whose moral agency is never viewed as having been corrupted in virtue of their participation in the practice.

\section{(b) Limits on Harm Reduction}

Another way in which to appreciate the distinctiveness of - and the normative superiority of-FRD-based harm reduction relative to consequentialism is by attending to the different ways in which they deal with the question of the moral limits of the harm reduction approach. Thus far, we have distinguished them by comparing the very different attitudes that they evince toward those policy debates that fall uncontroversially within the ambit of harm reduction. I now want to focus on the way in which they possess the capacity to express the difference between practices about which reasonable persons can disagree, and practices that fall beyond the bounds of what might be considered acceptable by reasonable persons.

In On Compromise and Rotten Compromise, Avishai Margalit makes the argument that there are certain compromises that we are duty-bound to refuse, even if by accepting them we would minimize certain harms [16]. Margalit makes the argument in the context of decisions that had to be made by the Allies about whether or not to compromise with the Nazis in order to save lives, but his point generalizes. There are certain compromises through which we make ourselves complicit in the partial acceptance of values that are incompatible with a society built on the values of equality of all persons and mutual respect. Though the line is difficult to draw, there are clearly compromises the acceptance of which involves us in compromising ourselves and our moral integrity. Now clearly, harm reduction involves a kind of compromise. It involves an agreement to "change the subject" and to discussing the regulation of a disputed practice not in terms of final values such as autonomy, dignity, non-commodification, and so on, but in terms of a language of harms that can be shared with those with whom we disagree about such ultimate values. This way of thinking about the logic of harm reduction implies that there are occasions when agreeing to change the subject in this way is unacceptable because it involves us in giving weight to normative considerations that are valueless, the acceptance of which, to follow Margalit, involves us in denying the very values that make decent societies possible.

\footnotetext{
${ }^{8}$ I thank both the anonymous readers of the original version of the paper for having pressed me on this point.
} 
Harm reduction grounded in the fact of unenforceability does not obviously have room for this thought. Since it seeks to minimize harms in all cases in which the attempt at enforcement gives rise to negative consequences, it cannot express the thought that there may be practices with respect to which it might be preferable to continue to attempt to enforce prohibitions, even though these prohibitions may very well be sub-optimal from a consequentialist standpoint. Prohibitions such as those found in the criminal law do not only have consequentialist justifications. They also allow a society to express its ultimate commitments. Though the expressive function of these kinds of prohibitions must be used parsimoniously, there may very well be practices that defy the most uncontroversial values of a decent society, and with respect to which harm reduction approaches may be morally deficient. To put the point more concretely, FRD-based harm reduction provides us with a theoretically elegant way to place policy debates about which reasonable people can disagree on one side of the line, and practices that are rightly subjected to moral condemnation such as female genital mutilation, on the other.

\section{(c) The Politics of Harm Reduction}

I've argued thus far that FRD-based harm reduction is superior to FU harm reduction because it better fits with the non-judgmental ethos that has been at the heart of the harm reduction approach from its inception, but also because it better allows to account for the moral limits that a practice of harm reduction should recognize if it is not to give rise to what Margalit has called "rotten" compromises. In this final section, I want to suggest that the politics that are associated with these two ways of construing harm reduction also differ, and that the politics of FRD-based harm reduction are more attractive in the context of a (broadly construed) liberal democracy.

The politics of the conception of harm reduction that stems from disagreement is, ultimately, I would argue, deliberative. It views the formulation of policy with respect to practices and kinds of behaviour that reasonable persons can disagree about as grounded in deliberative procedures through which citizens and their representatives can make policy that is respectful of others despite persistent disagreement. Let us refer to this form of harm reduction as deliberative harm reduction. Deliberative harm reduction views the task of determining which of the various kinds of harms associated with a practice and with different ways of regulating it as a matter for deliberation and compromise. Though no metric exists which might determine which policy best minimizes harm, reasonable persons can compromise on a mix of measures that address the various harms with which they are variously concerned. For deliberative harm reduction, the plurality of conceptions of harm and the corresponding absence of a metric with which to determine which policy is optimal from the point of view of the reduction of harm is a feature rather than a bug. Harm reduction on this view is about (re-)framing the debate around consequences rather than around ultimate, categorical principles. It is about framing compromises with which all can be reconciled rather than about arriving at determinate conclusions in a non-deliberative manner. 
The politics of harm reduction that emanates from non-enforceability, to the contrary, seems ultimately grounded in a more technocratic, managerial logic. Harm reduction is on this conception necessitated not by an awareness of irresolvable moral disagreement at the level of first-order values, but by the determination that that prohibition, presumably conceived of as the first-best option, is unavailable for technical or economic reasons. For technocratic harm reduction, pluralism and the absence of metric are a frustration. To the extent that it is born of an assessment of (technocratically ascertainable) costs, the logic of this way of thinking of harm reduction inclines it toward a similarly technocratic solution to the policy puzzle of which among a set of possible policies should be preferred. Pluralism and the absence of a metric, which I maintain are central to a theoretical extrapolation of practices of harm reduction, do not sit well with this logic.

\section{Conclusion}

I've argued in this short paper for a certain way of justifying and of understanding the moral impulse behind harm reduction approaches to public policy. I've suggested that it is most naturally integrated into a picture of society in which reasonable persons who evince attitudes of mutual respect toward one another try to find ways of dealing with their disagreements that express that mutual respect. Much more work needs to be done in order to flesh the approach out as a distinctive theory. In particular, the question of the moral limits of harm reduction must be given close attention, as does that of delineating with greater precision than I could in the context of a short paper the deliberative processes through which the FRD-based harm reduction can give rise to determinate resolutions of controversial policy debates.

Funding This study was funded by the Canadian Institutes for Health Research (Grant Number 376924).

\section{Compliance with Ethical Standards}

Conflict of interest The author declares that he has no conflict of interest.

\section{References}

1. Beirness, D. J., et al. (2008). Harm reduction. What's in a name. Ottawa: Canadian Center on Substance Abuse.

2. Christie, T., Groark, L., \& Sweet, W. (2008). Virtue ethics as an alternative to deontological and consequential reasoning in the harm reduction debate. International Journal of Drug Policy, 19(1), 52-58.

3. Cusick, L. (2006). Widening the harm reduction agenda: From drug use to sex work. International Journal of Drug Policy, 17, 3-11.

4. Dea, S. (2016). A harm-reduction approach to abortion. In S. Stettner (Ed.), Without apology: Writings on abortion in Canada. Edmontan: University of Athabasca Press.

5. Dworkin, G., Frey, R. G., \& Bok, S. (1998). Euthanasia and physician-assisted suicide. Cambidge: Cambridge University Press.

6. Flanigan, J., \& Watson, L. (2019). Debating sex work. Oxford: Oxford University Press. 
7. Gauthier, S., et al. (2013). L'utilisation de l'approche de la réduction des méfaits auprès des femmes qui ne quittent pas une situation de violence conjugale. In Massé and Mondou (pp. 159-188).

8. Godlee, F., \& Hurley, R. (2016). The war on drugs has failed. BMJ, 2016(355), i6067. https://doi. org/10.1136/bmj.i6067.

9. Heilig, S., \& Jamison, S. (1996). Physician aid-in-dying: toward a "harm reduction" approach. Cambridge Quarterly of Health Care Ethics, 5, 113-120.

10. Husak, D., \& de Marneffe, P. (2006). The legalization of drugs. Cambridge: Cambridge University Press.

11. Kingston, S., \& Thomas, T. (2018). No model in practice: A 'Nordic model' to respond to prostitution. Crime, Law, and Social Change, 71(410), 423-439.

12. Kleinig, J. (2008). The ethics of harm reduction. Substance Use and Misuse, 43(1), 1-16.

13. Kutscher, E., \& Greene R. E. (2020). A harm-reduction approach to coronavirus disease 2019. JAMA Health Forum https://jamanetwork.com/channels/health-forum/fullarticle/2766837.

14. Maccoun, R. J. (2012). Moral outrage and opposition to harm reduction. Criminal Law and Philosophy, 7(1), 83-98.

15. Magnusson, R. S. (2004). "Underground Euthanasia" and the harm minimization debate. Journal of Law, Medicine \& Ethics, 32, 486-498.

16. Margalit, A. (2013). On compromises and rotten compromises. Princeton: Princeton University Press.

17. Mondou, I. (2013). De la définition de la réduction des méfaits: consensus et divergences. In R. Massé \& I. Mondou (Eds.), Réduction des méfaits et tolérance en santé publique: enjeux éthiques et politiques. Ste. Foy: Presses de l'Université Laval.

18. O'Hare, P. (2007). Merseyside, the first harm reduction conferences, and the early history of harm reduction. International Journal of Drug Policy, 18(2), 141-144.

19. Roe, G. (2005). Harm reduction as paradigm: Is better than bad good enough? The origins of harm reduction. Critical Public Health, 15(3), 243-250.

20. Shell-Duncan, B. (2001). The medicalization of female circumcision: Harm reduction or promotion of a dangerous practice. Social Science and Medicine, 52, 1013-1028.

21. Weinstock, D. (2006). A neutral conception of reasonableness? Episteme, 3(3), 234-247.

Publisher's Note Springer Nature remains neutral with regard to jurisdictional claims in published maps and institutional affiliations. 